\title{
Is there an immunohistochemical technique definitively valid in epidermal growth factor receptor assessment?
}

\author{
FRÉDÉRIQUE PENAULT-LLORCA ${ }^{1}$, ANNE CAYRE $^{1}$, LAURENT ARNOULD $^{2}$, FRÉDÉRIC BIBEAU ${ }^{3}$, \\ MARIE-PIERRE BRALET ${ }^{4}$, PHILIPPE ROCHAIX ${ }^{5}$, JACQUELINE SAVARY $^{6}$ and JEAN-CHRISTOPHE SABOURIN ${ }^{7}$ \\ ${ }^{1}$ Centre Jean Perrin, Department of Pathology, 63011 Clermont-Ferrand; UEFR medecine UdA; UMR484, \\ Clermont-Ferrand; ${ }^{2}$ Centre G.F. Leclerc, Department of Pathology, 21000 Dijon; ${ }^{3}$ Centre Val d'Aurelle, \\ Department of Pathology, 34298 Montpellier; ${ }^{4}$ Paul Brousse Hospital, Department of Pathology, 94804 Villejuif; \\ ${ }^{5}$ Centre Claudius Regaud, Department of Pathology, 31052 Toulouse; ${ }^{6}$ Merck Lipha Santé, 37 rue Saint Romain, \\ 69379 Lyon Cédex 08; ${ }^{7}$ Charles Nicolle Hospital, Department of Pathology, 76031 Rouen, France
}

Received March 23, 2006; Accepted June 19, 2006

\begin{abstract}
Immunohistochemistry (IHC) is required for the selection of patients for a monoclonal antibody based targeted treatment with $\mathrm{C} 225$ (Erbitux ${ }^{\circledR}$ ). To validate the usefulness of IHC, the confirmation of assays and scoring systems are mandatory. In an attempt to standardize the immunohistochemical detection of the epidermal growth factor receptor (EGFR), we retrospectively evaluated three commercially available EGFR kits or antibodies and analyzed the discrepancies between the tests in terms of the percentage of positive cells, intensity, cut-off value and fixatives. We extracted 232 paraffin-embedded samples from a metastatic colorectal cancer clinical trial. For all the cases, EGFR expression was assessed with the FDA approved Dako EGFR pharmaDx kit, the Zymed EGFR kit and the Ventana EGFR 3C6 antibody. Different cut-off values were tested, and the intensity was scored $0,1^{+}, 2^{+}, 3^{+}$following Dako's recommendations. The percentage of positive cases varied from 93 to $75 \%$ with a cut-off of value $1 \%$ of positive cells, from 80 to $61 \%$ with a cut-off of $5 \%$ positive cells and from $72 \%$ to $48 \%$ with a cut-off value of $10 \%$. Both Ventana and Zymed tests were more sensitive than the Dako test (Ventana $>$ Dako; $\mathrm{p}<10^{-7}$, Zymed $>$ Dako; $\left.\mathrm{p}=2.10^{-6}\right)$. No difference was noted between Ventana and Zymed tests $(\mathrm{p}=0.75)$. A high concordance was observed for the 3 tests for the evaluation of high intensities. The use of a scoring system combining the percentage of positive cells and intensity was not useful for Zymed and Ventana as the intensity of staining is
\end{abstract}

Correspondence to: Dr Frédérique Penault-Llorca, Centre Jean Perrin, Département de Pathologie, BP 392, 58 rue Montalembert, 63011 Clermont-Ferrand cedex, France

E-mail: fpenault@cjp.fr

Key words: epidermal growth factor receptor, colorectal cancer, immunohistochemistry, quality assurance correlated to the percentage of positive cells: Ventana $(\mathrm{p}<10$ $\left.{ }^{6}\right)$ and Zymed $\left(\mathrm{p}<10^{-5}\right)$. No interaction with staining was identified for any of the fixatives, or with the nature of samples received (i.e. slides vs blocks, biopsies vs surgical specimens). Our data showed a higher percentage of positive cells detected by Ventana and Zymed tests, whatever the cutoff value for positivity. No scoring system showed, to date, its accuracy, and more studies have to be conducted with an evaluation of the response to cetuximab, possibly with a correlation with FISH amplification in colorectal carcinoma.

\section{Introduction}

The epidermal growth factor receptor (EGFR) is a transmembrane glycoprotein belonging to the erb tyrosine kinase family receptor including EGFR (HER1 or erb-B1), erbB-2 (HER2), erbB-3 (HER3) and erbB-4 (HER4). EGFR is activated in many tumours, including colorectal cancer (CRC). Its activation has effects on the signalling pathways affecting cellular growth, differentiation and proliferation (1). EGFR appears to be a major target in colorectal cancer. EGFR overexpression by immunohistochemistry (IHC) in colorectal cancer ranged from $53 \%$ to $>90 \%$ using different IHC tests $(2,3)$. The rationale for targeted therapies against the EGFR axis in colorectal cancer is an attractive antitumour strategy based on the relative overexpression of EGFR in tumours as compared to normal tissues and the correlation between increased EGFR expression and poor clinical outcome (4). In colorectal tumours, the most highly developed of these antiEGFR approaches is the monoclonal antibody C225 or cetuximab $\left(\right.$ Erbitux $\left.^{\circledR}\right)$ directed against the external domain. In different trials, the selection of the patients for EGFR-targeted treatment by cetuximab was actually made by IHC, based on the wisdom that a target should be present as a prerequisite to targeted therapy. However, it should be noted that these studies found no association between the presence of tumour immunoreactivity for EGFR, the intensity of staining or the percentage of positive cells and likelihood of response $(5,6$; Adenis A, et al, Proc ASCO, abs. 3630, 2005). Moreover, Chung et al showed that patients with EGFR-negative 
A

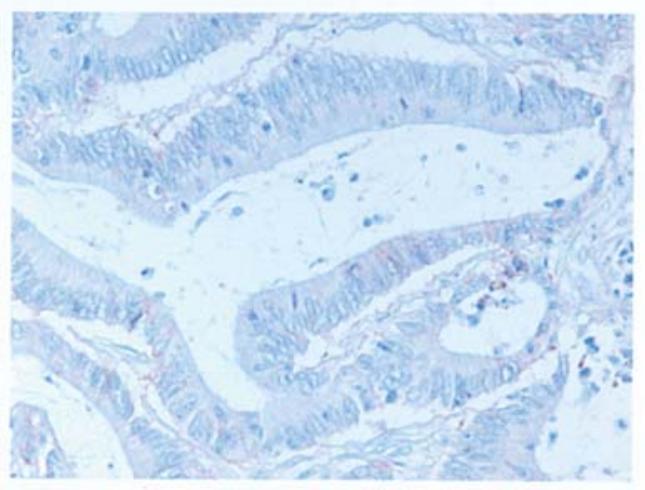

C

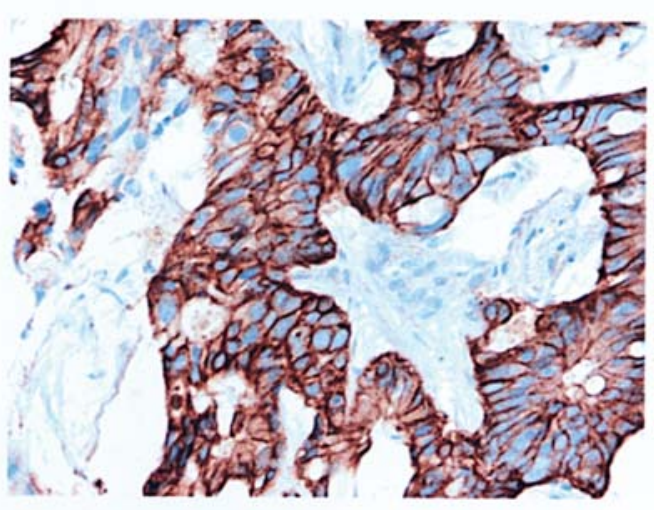

B

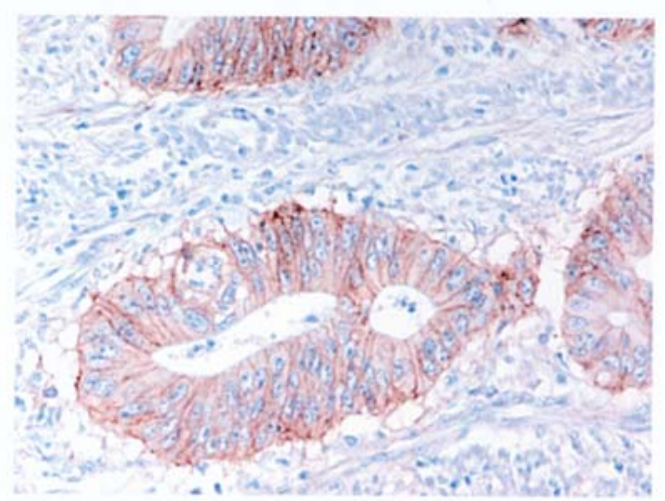

D

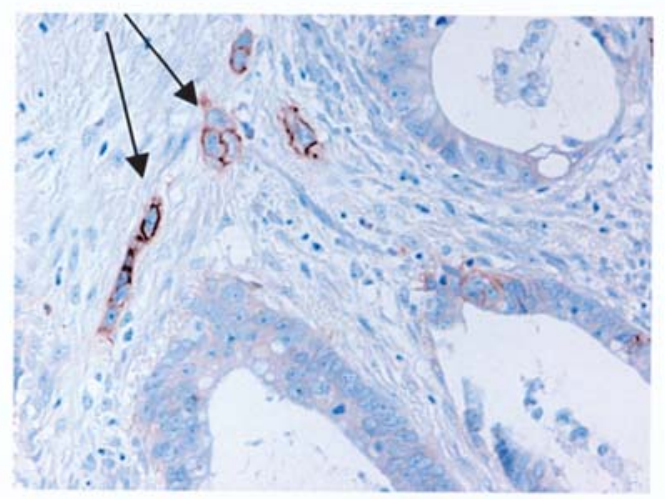

Figure 1. Definition of intensity scoring. EGFR scoring - intensity of membrane scoring, complete or incomplete. (A) $1^{+}$weak. (B) Moderate. (C) Strong. (D) Usual pattern of staining in colorectal cancer, restricted to few cells in the invasion front ( $\left.3^{+}\right)$(arrow). Stainings with the Ventana EGFR 3 C6 antibody.

tumours have the potential to respond to cetuximab-based therapies (7). These reports have made the use of IHC for patient selection questionable.

IHC is a widely developed technique which is known to have potential variability. This can be explained by the different types of antibody used, the variability in the assays and heterogeneity of the samples (tumour types, type of samples, fixation). Before excluding IHC for the purpose of selecting for cetuximab as suggested by Chung et al and Saltz $(7,8)$, we decided to compare three commercially available antibodies directed against EGFR. We have analyzed the discrepancies between the tests in terms of the percentage of positive cells, intensity, cut-off values and fixatives.

\section{Materials and methods}

Tumour specimens. A series of 232 cases of metastatic colorectal cancer (225 primary tumours and 7 metastases) from patients involved in a clinical trial were tested for EGFR expression. We received cut slides for 83 cases and 149 paraffin blocks (for some cases we received more than one block). Thirteen biopsies (6\%) and 219 surgical specimens (94\%) were examined. Different fixatives were used: 173 samples were formalin-fixed (74\%), 14 AFA-fixed (6\%), 15 Bouin-fixed (7\%). Fixation was unknown for 30 cases (13\%).

Immunohistochemistry. The blocks were cut into $4 \mu \mathrm{m}$ sections in the laboratory just before IHC. The blank sections received from outside laboratories were prepared $24 \mathrm{~h}$ before shipping to our laboratory using overnight mail. On reception, they were stored in the dark at $-4^{\circ} \mathrm{C}$. IHC was carried out at the latest in the two days following. For each case, the EGFR expression was assessed using the Food and Drug Administration (FDA) approved Dako EGFR pharmaDx kit, the Zymed EGFR kit and the Ventana EGFR 3C6 antibody following the manufacturer's recommendations. Dako IHC was performed on all the cases, Ventana on 208 cases and, 196 were tested with Zymed. The missing cases are due to lack of material when only blank slides were received.

Evaluation of the slides. Slide evaluation was first performed by one pathologist (F.P-L.) and then all the slides were reviewed by a panel of five pathologists (L.A., F.B., M-P.B., P.R., J-C.S.) who were not aware of the first results. All the discrepant cases were reviewed with the referent pathologist. The overall inter-observer difference was $<5 \%$. In the case of differing results, a consensus was reached by joint evaluation. The staining pattern of tumour cell membranes was further classified using incomplete membrane staining (staining of only part of the tumour cell membrane) or complete membrane staining (circumferential staining of the entire tumour cell membrane). We reported the percentage of positive cells (with complete or incomplete membrane staining). Intensity was scored as $0,1^{+}$(weak), $2^{+}$(moderate), and $3^{+}$(strong) (Fig. 1). When the staining was heterogeneous, the final intensity was determined by the highest one. 


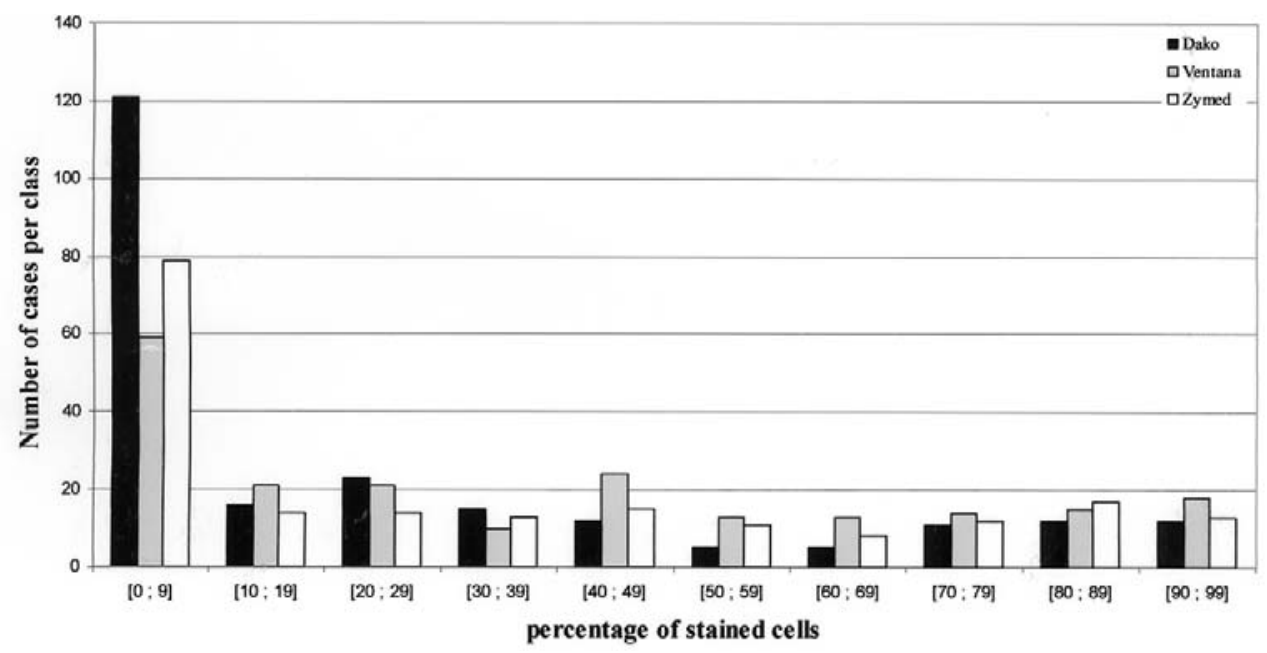

Figure 2. Repartition of the percentage of positive cells according to the antibody used.

Table I. Proportion of stained cells according to the cut-off value using three different monoclonal anti-EGFR antibodies.

\begin{tabular}{lccc}
\hline & $\begin{array}{c}\text { Dako } \\
(\mathrm{n}=232)\end{array}$ & $\begin{array}{c}\text { Ventana } \\
(\mathrm{n}=208)\end{array}$ & $\begin{array}{c}\text { Zymed } \\
(\mathrm{n}=196)\end{array}$ \\
\hline Cut-off value 1\% & $75 \%$ & $93 \%$ & $86 \%$ \\
Cut-off value 5\% & $61 \%$ & $80 \%$ & $78 \%$ \\
Cut-off value 10\% & $48 \%$ & $72 \%$ & $60 \%$ \\
\hline
\end{tabular}

Scoring systems. Different cut-off values were tested to define a positive case i.e., $>1 \%$ positive cells, $>5 \%$ positive cells or $>10 \%$. We also tried to classify the results only by intensity: Scores $0,1^{+}, 2^{+}, 3^{+}$, as some cases displayed very few highly positive cells in the invasion front. A combined score (percentage of positivity, intensity) was also evaluated. Intensity ranged from 0 to 3 , and the percentage of positive cells was classified from 0 to $5(0: 0 \%, 1: 1 \%, 2: 1$ to $5 \%, 3$ : 5 to $20 \%, 4: 20$ to $50 \%$, and $5:>50 \%)$. The score was established by the addition of the intensity and the percentage of positive cells (values from 0 to 8 ).

Statistics. The statistical analyses were performed with a Kruskal and Wallis's $\mathrm{H}$ test to compare categorical with quantitative data and with the Spearman ranks correlation test according to the abnormal distributions or inequality of variances when two quantitative parameters were compared. A p-value of $<0.05$ was considered significant.

\section{Results}

Percentage of positive cells according to the antibody used. The repartition of the percentage of stained cells in relation to the type of antibody was first evaluated (Fig. 2). It is obvious that the class of $0-10 \%$ positive cells was the only one different from the others. When the value was $>10 \%$ the distribution was balanced. So, we decided to evaluate three different cut-off values: $1 \%, 5 \%$ and $10 \%$ positive cells.
Percentage of positive cells. The percentage of positive cases varied from 75 to $93 \%$ with a cut-off value of $1 \%$ of positively stained cells, from 61 to $80 \%$ with a cut-off of $5 \%$ positively stained cells and from $48 \%$ to $72 \%$ with a cut-off value of $10 \%$ (Table I). The Ventana antibody was more sensitive than the Dako, it stained 13 (30\% of additional cells $\left(\mathrm{p}<10^{-7}\right)$. The Zymed kit stained 9 (27\% of additional cells $\left(\mathrm{p}<10^{-5}\right)$. No significant difference was noted between the Ventana and Zymed tests $(\mathrm{p}=0.75)$. Eight cases were negative for the three antibodies with a cut-off value of $1 \%$, and for this cut-off, 58 patients were negative with the Dako test. Among them, 42 were positive with the Ventana test and 29 with the Zymed test (Table II).

Intensity score. The percentage of $3^{+}$cases was $34 \%, 33 \%$ and $30 \%$ for Dako, Ventana and Zymed, respectively (Table III). Some $3^{+}$cases were homogeneous (23\% for Dako, $13 \%$ for Ventana and $9 \%$ for Zymed) and some were heterogeneous and also contained $2^{+}$stained cells.

Combined score. The concordance between the percentage of stained cells and the intensity of staining was obviously always $100 \%$ for the negative cases $(0 \%$ stained cells of intensity of 0 ). To study the correlation between the percentage of stained cells and intensity, the negative cases had to be withdrawn. For Zymed and Ventana, as the intensity of staining was linked to the percentage of positive cells: Ventana $\left(\mathrm{p}<10^{-6}\right)$ and Zymed $\left(\mathrm{p}<10^{-5}\right)$, the use of a combined score was not useful. For the Dako test, there was no correlation between the percentage of stained cells and intensity $(\mathrm{p}=0.61)$. It should be noted that for the Dako $3^{+}$ cases, $30 \%$ had only $1 \%$ positive cells (score 4 ). Those $3^{+}$ cells were highlighted with the 3 antibodies (Fig. 3).

Interaction between staining and specimen preparation. No interaction with staining was identified for any of the fixatives, nor with the nature of samples (i.e., slides vs blocks, biopsies vs surgical specimens). The advantage of the Dako and Ventana tests was that the procedure can be fully automated. With regards to interpretation, the most contrasted slides were obtained with the Ventana test. The Zymed test was the least expensive. 
Table II. Details of the 58 EGFR-negative Dako cases with a cut-off value of $1 \%$ of staining cells according the two other antibodies, Ventana and Zymed.

\begin{tabular}{|c|c|c|c|c|c|c|}
\hline & Ventana & Zymed & & Zymed & & \\
\hline \multirow{3}{*}{ Missing cases } & \multirow{3}{*}{6} & Missing cases & 2 & \multirow{3}{*}{8} & Missing cases & 2 \\
\hline & & + & 1 & & + & 4 \\
\hline & & - & 3 & & - & 2 \\
\hline \multirow{3}{*}{+} & \multirow{3}{*}{42} & Missing cases & 4 & \multirow{3}{*}{29} & Missing cases & 1 \\
\hline & & + & 28 & & + & 28 \\
\hline & & - & 10 & & - & 0 \\
\hline \multirow{3}{*}{ - } & \multirow{3}{*}{10} & Missing cases & 2 & \multirow{3}{*}{21} & Missing cases & 3 \\
\hline & & + & 0 & & + & 10 \\
\hline & & - & 8 & & - & 8 \\
\hline
\end{tabular}

Table III. Intensity of staining using three different monoclonal anti-EGFR antibodies.

\begin{tabular}{lccc}
\hline Intensity & $\begin{array}{c}\text { \% of Dako } \\
\text { cases }\end{array}$ & $\begin{array}{c}\text { \% of Ventana } \\
\text { cases }\end{array}$ & $\begin{array}{c}\text { of Zymed } \\
\text { cases }\end{array}$ \\
\hline 0 & 25 & 8 & 14 \\
$1^{+}$ & 6 & 14 & 15 \\
$2^{+}$ & 35 & 45 & 41 \\
$3^{+}$ & 34 & 33 & 30 \\
$\%$ positive & 75 & 92 & 86 \\
cases & & & \\
\hline
\end{tabular}

\section{Discussion}

This study is to our knowledge the first to directly compare three commercially available tests directed against the EGFR. This comparison is important because a positive IHC EGFR test was required for the involvement of patients in trials with cetuximab including the BOND trial and the MABEL trial, and is now a prerequisite for this treatment in patients with metastatic CRC $(5,6)$. EGFR IHC detection was performed in the cetuximab trials using the FDA approved EGFR PharmDx kit (DakoCytomation).

Our results showed that the three tests are clearly not equivalent. The percentage of positive cells was significantly lower for the Dako test. This directly impacts patient eligibility for anti-EGFR therapy. For instance, if the score for positivity is $1 \%$ of positive cells (as used in the BOND or Mabel Studies), 42 or 29 patients would have been excluded with the Dako test compared to the Ventana or Zymed test, respectively. Using the Ventana test, only 8 patients would not have been treated. This means that almost every patient could be eligible for cetuximab, which makes us and others $(7,8)$ wonder about the role of IHC in patient selection. Moreover, 7 negative patients out of 16 have reportedly responded to cetuximab based therapy (7). In this study, the patients were tested with another Ventana clone 31G7 which is different than that actually recommended by Ventana: EGFR 3C6. We tested $31 \mathrm{G} 7$ and in our opinion it was less sensitive than 3C6 (data not shown). A recent study showed that $31 \mathrm{G} 7$ was comparable with the PharmDx kit antibody (9) and in the study of Chung et al, 14 cases were confirmed negative by the reference pathology review and those cases also tested negative with the Dako kit (7). As these two tests may yield a lower number of positive cases, one could argue that some of the negative cases of this report could have been positive if they were tested by Ventana 3C6 or the Zymed test used in our current study. Four antibodies were used in the recent studies of EGFR expression and according to our study, showed that they were not equivalent in terms of the percentage of positive cells (Table IV) (10-16).

The approval of cetuximab is currently restricted to those patients whose tumours express EGFR. However, there is no indication as to what the definition of EGFR expression is. In the recent EGFR trials, the patients were enrolled on the basis of $1 \%$ or more malignant cells that stained for EGFR (complete or incomplete membrane staining whatever the intensity) on immunohistochemical analysis with the Dako EGFR PharmDx kit $(5,6)$. This cut-off value was chosen arbitrarily. In other trials with tyrosine kinase inhibitors, different cut-off values were retrospectively chosen (such as $>10 \%$ positive cells). A recent review of the current test methods for EGFR status reported the lack of a consensus concerning the scoring for EGFR staining and the cut-off value for positivity (17). A specific drawback of the scoring systems is that they are not strictly quantitative and the interpretation of stained samples is a subjective process. Dako recommends another scoring system, i.e., score 0 , no staining or unspecific staining of tumour cells; score $1^{+}$, weak (intensity) and incomplete staining of $>10 \%$ of tumour cells; score $2^{+}$, moderate and complete staining of $>10 \%$ of tumour cells; score $3^{+}$, strong and complete staining of $>10 \%$ of tumour cells (18). In our experience, this scoring is difficult to use as the pattern of staining in CRC is frequently heterogeneous. Furthermore, sometimes, the invasion front is strongly stained but the percentage of positive cells is $<10 \%$ for the whole tumour. Nevertheless, such a case has, in our opinion, to be classified as positive even though it would be 
A

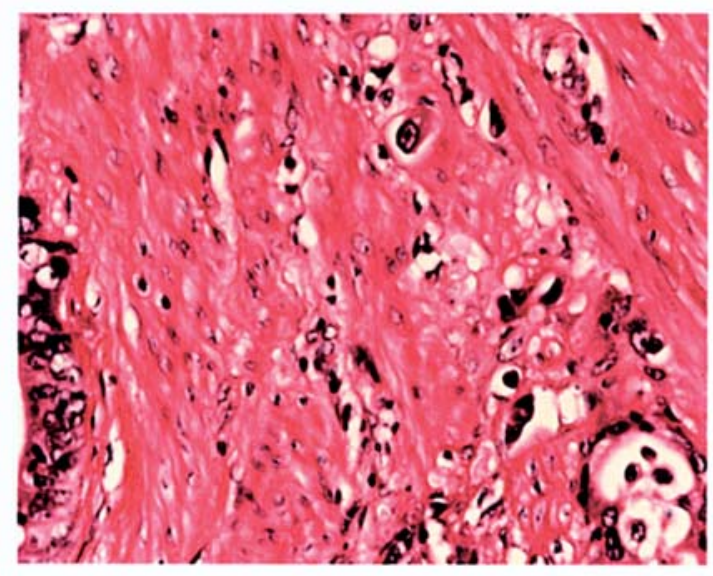

C

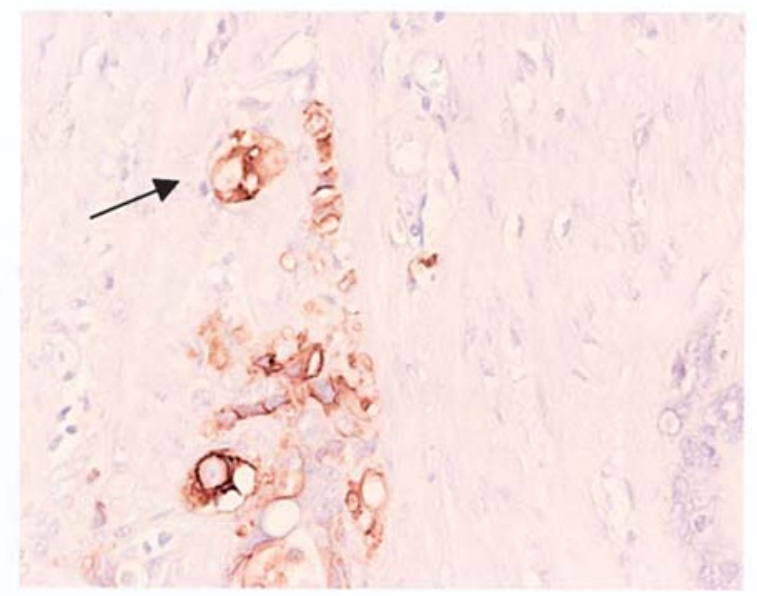

B

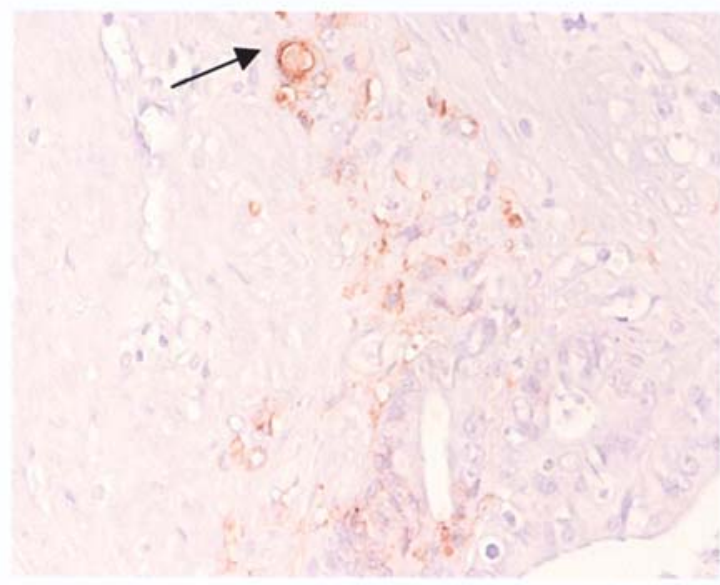

D

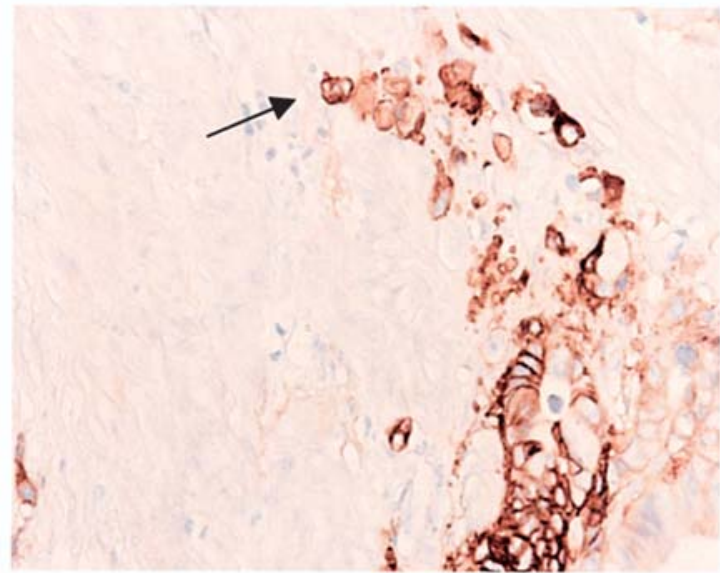

Figure 3. Staining of the invasion front with the different antibodies. Example of $3^{+}$cases (x200). (A) HES staining of the tumour gland with isolated tumour cells. (B) $3^{+}$staining on few isolated cells (Dako EGFR pharmaDx kit). (C) $3^{+}$staining of more tumour cells and glands (Zymed EGFR kit). (D) $3^{+}$staining of the majority of the tumour cells and glands (Ventana EGFR 3C6 antibody). Few $3^{+}$cells are highlighted by the three tests (arrow), and therefore not missed by less sensitive cases such as the Dako EGFR pharmaDx kit.

Table IV. Percentage of stained cells of colon adenocarcinoma with different commercially available antibodies.

\begin{tabular}{|c|c|c|c|c|}
\hline Antibody & Clone & Authors & $\begin{array}{l}\text { Tumour with } \geq 1 \% \\
\text { of stained cells }(\%)\end{array}$ & $\begin{array}{l}\text { Patient } \\
\text { no. }\end{array}$ \\
\hline \multirow[t]{2}{*}{ Novocastra } & EGFR 113 & Ooi A et al, 2004 (10) & 8 & 244 \\
\hline & EGFR 113 & Spano JP et al, 2005 (11) & 97 & 150 \\
\hline \multirow[t]{2}{*}{ Ventana } & $3 \mathrm{C} 6$ & Bralet MP et al, 2005 (12) & 95 & 40 \\
\hline & $3 \mathrm{C} 6$ & Present study & 93 & 208 \\
\hline \multirow[t]{2}{*}{ Zymed } & $31 \mathrm{G} 7$ & Ogino S et al, 2005 (13) & 85 & 27 \\
\hline & $31 \mathrm{G} 7$ & Present study & 86 & 196 \\
\hline \multirow[t]{7}{*}{ Dako PharmDX } & $18 C 9$ & Goldstein NS et al, 2001 (2) & 76 & 102 \\
\hline & $18 C 9$ & Cunningham D et al, 2004 (5) & 82 & 577 \\
\hline & $18 \mathrm{C} 9$ & Scartozzi M et al, 2004 (14) & 53 & 99 \\
\hline & $18 C 9$ & Resnick MB et al, 2004 (15) & 80 & 134 \\
\hline & $18 \mathrm{C} 9$ & Blanchot-Jossic F et al, 2005 (16) & 82 & 39 \\
\hline & $18 \mathrm{C} 9$ & Bhargava R et al, 2006 (9) & 92 & 314 \\
\hline & $18 \mathrm{C} 9$ & Present study & 75 & 232 \\
\hline
\end{tabular}


a 0 in the Dako's classification. Different scoring systems were proposed $(2,7,18,19$; Tse C et al, Proc ASCO, abs. $3607,2005)$. Some of them are only based on the percentage of positive cells (10), one on the intensity (17), and others are combined scores with intensity, and the percentage of positive cells (17). Different cut-off values were tested in the present study and Dako test was less sensitive except for the detection of highly stained $\left(3^{+}\right)$cases, which were not missed by this kit. This difference in sensitivity is not due to technical problems as we could not find any interaction with staining for any of the fixatives, nor with the nature of samples received i.e., slides vs blocks, biopsies vs surgical specimens. One of the reasons for this is that the blocks were cut just before IHC and the cut slides received were kept for a maximum of $64 \mathrm{~h}$ at room temperature before processing. Therefore, no antigenic loss could occur. Atkins et al showed that a long-term storage of cut slides at room temperature directly affects the epitope preservation (18). This phenomenon did not apply to our study. Nevertheless, a major issue for EGFR testing is the possibility of false negatives or disproportionately low staining that can occur from a lack of sensitivity of some methods, or the heterogeneity of EGFR expression within different tumour regions.

Among the other approaches used to evaluate EGFR status, mutational status and EGFR amplification showed promising results for the selection of patients for EGFR targeted therapies (20). However, mutations involving the kinase domain do not occur in CRC compared to lung cancer, and would not be useful in CRC (20). Fluorescent in situ hybridization (FISH) could be interesting in CRC as reported by Moroni et al (19). In this study, the authors suggest that CRC patients could be selected for cetuximab treatment on the basis of the EGFR gene copy number. They observed that 8/9 responders had tumours with increased EGFR copies and $1 / 21$ of the non-responders had an increased EGFR copy number, they did not correlate the level of amplification to the IHC score. A recent report showed that amplification in CRC was rare $(4.5 \%)$ and only found in $3^{+}$patients (using the Dako score and the Novocastra antibody) (10). However, considering both the high cost and the technical complexity of FISH, a judicious approach for the clinical setting would be to limit the use of this technique to the category of $3^{+}$ expressing colorectal cancer. More studies still need to be conducted as the relationship between gene amplification and protein expression may well turn out to vary with tumour type, or even the stage of tumour development.

In conclusion, our results favour the use of the Ventana 3C6 test or the Zymed kit rather than the Dako EGFR pharmaDx kit which lacks sensitivity. But, at this stage, we are not sure that the major requirement for an EGFR test is high sensitivity. For high intensity staining, we observed that the $3^{+}$cases with Dako frequently had a lower percentage of positive cells, but these $3^{+}$cells were also found with the other antibodies, and were located in the deepest regions of invasion. We have, to date no answer concerning the predictive or prognostic value of positive $1^{+}$or $2^{+}$cells highlighted with the other antibodies. The standardization of techniques to determine EGFR overexpression should be considered a priority. IHC remains in our opinion currently the best choice for routine clinical use, even if a universal scoring system is still needed to better compare research results.

\section{Acknowledgements}

The authors thank Christiane Jullien for her excellent technical help and the companies Dako, Ventana and Zymed for generously providing the antibodies.

\section{References}

1. Mendelsohn J and Baselga J: Status of epidermal growth factor receptor antagonists in the biology and treatment of cancer. $\mathrm{J}$ Clin Oncol 21: 2787-2799, 2003.

2. Goldstein NS and Armin M: Epidermal growth factor receptor immunohistochemistry reactivity in patients with American Joint Committee on Cancer Stage IV colon adenocarcinoma: implications for a standardized scoring system. Cancer 92: 1331-1346, 2001.

3. Salomon DS, Brandt R, Ciardello F and Normanno N: Epidermal growth factor-related peptides and their receptors in human malignancies. Crit Rev Oncol Hematol 19: 183-232, 1995.

4. Lockhart $\mathrm{C}$ and Berlin JD: The epidermal growth factor receptor as a target for colorectal cancer therapy. Semin Oncol 32: 52-60, 2005.

5. Cunningham D, Humblet Y, Siena S, Khayat D, Bleiberg H, Santoro A, Bets D, Mueser M, Harstrick A, Verslype C, Chau I and Van Cutsem E: Cetuximab monotherapy and cetuximab plus irinotecan in irinotecan-refractory metastatic colorectal cancer. N Engl J Med 351: 337-345, 2004.

6. Saltz LB, Meropol NJ, Loehrer PJ, Needle MN, Kopit J and Mayer RJ: Phase II trial of cetuximab in patients with refractory colorectal cancer that expresses the epidermal growth factor receptor. J Clin Oncol 22: 1201-1208, 2004.

7. Chung KY, Shia J, Kemeny NE, Shah M, Schwartz GK, Tse A, Hamilton A, Pan D, Schrag D, Schwartz L, Klimstra DS, Fridman D, Kelsen DP and Saltz LB: Cetuximab shows activity in colorectal cancer patients with tumors that do not express the epidermal growth factor receptor by immunohistochemistry. J Clin Oncol 23: 1803-1810, 2005.

8. Saltz L: Epidermal growth factor receptor-negative colorectal cancer: is there truly such an entity? Clin Colorectal Cancer 5: S98-S100, 2005.

9. Bhargava R, Chen B, Klimstra DS, Saltz LB, Hedvat C, Tang LH, Gerald W, Teruya-Feldstein J, Paty PB, Qin J and Shia J: Comparison of two antibodies for immunohistochemical evaluation of epidermal growth factor receptor expression in colorectal carcinomas, adenomas, and normal mucosa. Cancer: Published Online, 10 Mar, 2006.

10. Ooi A, Takehana T, Li X, Suzuki S, Kunitomo K, Iino H, Fujii H, Takeda Y and Dobashi Y: Protein overexpression and gene amplification of HER-2 and EGFR in colorectal cancers: an immunohistochemical and fluorescent in situ hybridization study. Mod Pathol 17: 895-904, 2004.

11. Spano JP, Lagorce C, Atlan D, Milano G, Domont J, Benamouzig R, Attar A, Benichou J, Martin A, Morere JF, Raphael M, Penault-Lorca F, Breau JL, Fagard R, Khayat D and Wind P: Impact of EGFR expression on colorectal cancer patient prognosis and survival. Ann Oncol 16: 102-108, 2005.

12. Bralet MP, Paule B, Adam R and Guettier C: Loss of epidermal growth factor receptor expression in lymph node and liver metastases of colon carcinoma. J Clin Oncol 23: 5844, 2005.

13. Ogino S, Meyerhardt JA, Cantor M, Brahmandam M, Clark JW, Namgyal C, Kawasaki T, Kinsella K, Michelini AL, Enzinger PC, Kulke MH, Ryan DP, Loda M and Fuchs CS: Molecular alterations in tumors and response to combination chemotherapy with gefitinib for advanced colorectal cancer. Clin Cancer Res 11: 6650-6656, 2005.

14. Scartozzi M, Bearzi I, Berardi R, Mandolesi A, Fabris G and Cascinu S: Epidermal growth factor receptor (EGFR) status in primary colorectal tumors does not correlate with EGFR expression in related metastatic sites: implications for treatment with EGFR-targeted monoclonal antibodies. J Clin Oncol 22: 4772-4778, 2004. 
15. Resnick MB, Routhier J, Konkin T, Sabo E and Pricolo VE: Epidermal growth factor receptor, c-MET, beta-catenin, and p53 expression as prognostic indicators in stage II colon cancer: a tissue microarray study. Clin Cancer Res 10: 3069-3075, 2004.

16. Blanchot-Jossic F, Jarry A, Masson D, Bach-Ngohou K, Paineau J, Denis MG, Laboisse CL and Mosnier JF: Upregulated expression of ADAM17 in human colon carcinoma: co-expression with EGFR in neoplastic and endothelial cells. J Pathol 207: 156-163, 2005.

17. Tos AP and Ellis I: Assessing epidermal growth factor receptor expression in tumours: What is the value of current test methods? Eur J Cancer 41: 1383-1392, 2005.
18. Atkins D, Reiffen KA, Tegtmeier CL, Winther H, Bonato MS and Storkel S: Immunohistochemical detection of EGFR in paraffin-embedded tumor tissues: variation in staining intensity due to choice of fixative and storage time of tissue sections. J Histochem Cytochem 52: 893-901, 2004.

19. Moroni M, Veronese S, Benvenuti S, Marrapese G, SartoreBianchi A, Di Nicolantonio F, Gambacorta M, Siena S and Bardelli A: Gene copy number for epidermal growth factor receptor (EGFR) and clinical response to anti-EGFR treatment in colorectal cancer: a cohort study. Lancet Oncol 6: 279-286, 2005.

20. Hirsch FR and Witta S: Biomarkers for prediction of sensitivity to EGFR inhibitors in non-small cell lung cancer. Curr Opin Oncol 17: 118-122, 2005. 